\title{
CONTROLE JUDICIAL DE CONSTITUCIONALIDADE, LEGITIMIDADE E SENSIBILIDADES JURÍDICAS: QUEM CONTROLA O CONTROLADOR?
}

\author{
JUDICIAL REVIEW, LEGITIMACY AND LEGAL SENSITIVITY: WHO CONTROLS \\ THE CONTROLLER?
}

\section{Fabrício Castagna Lunardi}

Doutor (2018) e Mestre (2014) em Direito pela Universidade de Brasília - UnB. Bacharelado em Direito (2004) e especialização em Direito Civil pela Universidade Federal de Santa Maria - UFSM, (2006). Juiz de Direito da Justiça do Distrito Federal e dos Territórios desde 2009. Membro do Grupo de Trabalho 'Decisões Criminais' na ENFAM - Escola Nacional de Formação e Aperfeiçoamento de Magistrados e do Grupo de Trabalho para Otimização de Julgamentos do Tribunal do Júri, no CNJ.

\section{Resumo}

O presente artigo tem o objetivo de mostrar que a revisão judicial não é autoevidente, tampouco lhe é inerente a ideia de proteção aos direitos fundamentais, bem como que é imprescindível criar mecanismos democráticos para controlar a instituição que exerce o controle de constitucionalidade. Nesse tocante, buscam-se investigar, sob uma perspectiva comparada, os sistemas de controle de constitucionalidade de outros países; os modelos de revisão judicial propostos para o Brasil na Assembleia Nacional Constituinte; as sensibilidades jurídicas brasileiras acerca de quem deve dar a resposta final em termos de controle de constitucionalidade; 0 déficit de participação democrática na revisão judicial; e como aumentar o controle sobre a instituição que exerce 0 controle de constitucionalidade. Para atingir os seus escopos, a pesquisa se desenvolve com base na opção de uma linha crítico-metodológica, bem como jurídico-comparativa. Entretanto, a par da perspectiva crítica e reflexiva, a investigação da presente pesquisa não se eximirá de ser jurídico-propositiva, mediante o oferecimento de alternativas ao modelo de controle de constitucionalidade brasileiro atual. Ao final, conclui-se que 0 modelo de revisão judicial forte não é autoevidente; que, no controle difuso de constitucionalidade, comparativamente ao abstrato, o poder de revisão judicial fica mais diluído entre as diversas instâncias judiciais, além do que se permite um maior controle, realizado pelas diversas instituições e pelos cidadãos; e que o controle de constitucionalidade deve ser apenas o medium 
pelo qual o Judiciário participa do projeto constitucional, sem fechar o diálogo com o futuro, com as demais instituições e com a sociedade.

Palavras-chave: Controle de constitucionalidade. Controle do controlador. Legitimidade. Democracia. Sensibilidades jurídicas.

\begin{abstract}
This paper aims to show that judicial review is not self-evident, nor is it inherent in the idea of protection of fundamental rights, as well as that it is essential to create democratic mechanisms to control the institution that controls constitutionality. In this regard, we seek to investigate, from a comparative perspective, the systems of control of constitutionality of other countries; the models of judicial review proposed for Brazil in the National Constituent Assembly; the Brazilian legal sensitivities about who should give the final answer in terms of constitutionality control; the lack of democratic participation in judicial review; and how to increase control over the institution that exercises the judicial review. To reach its scopes, the research is developed based on the option of a criticalmethodological as well as legal-comparative line. However, along with a critical and reflexive perspective, the investigation of the present research will not be exempt from being legal-propositional, by offering alternatives to the current model of Brazilian judicial review. In the end, it is concluded that the model of strong judicial review is not self-evident; that in the diffuse judicial review, compared to the abstract, the judicial power is more diluted among the various judicial bodies, in addition to allowing greater control, carried out by the various institutions and citizens; and that judicial review should be only the medium through which the Judiciary participates in the constitutional project, without closing the dialogue with the future, with other institutions and with society.
\end{abstract}

Key-words: Judicial Review. Control of the controller. Legitimacy. Democracy. Legal sensitivities. 


\section{CONSIDERAÇÕES INICIAIS}

Alguns estudos constitucionais brasileiros, sobretudo os com viés mais dogmático, têm proposto que um controle abstrato de constitucionalidade forte pelo Supremo Tribunal Federal seria o ápice do constitucionalismo brasileiro e da evolução na proteção dos direitos fundamentais. Além disso, por diversas vezes, têm ecoado na doutrina constitucional afirmações de que a jurisdição constitucional é quem dá sentido à Constituição e, inclusive, de que "a Constituição é aquilo que o Supremo Tribunal Federal diz que é"1. A crença nesses mitos tem levado diversos autores brasileiros ${ }^{2}$ a preconizar, inclusive, a necessidade de uma nova divisão de Poderes, com um acréscimo de funções normativas à Corte Constitucional.

Entretanto, a existência do modelo de controle abstrato de constitucionalidade pelo Judiciário não é autoevidente, tampouco the é inerente à ideia de proteção aos direitos fundamentais. Com efeito, há diversos sistemas constitucionais que adotam um modelo de controle judicial de constitucionalidade fraco, ou em que a última palavra em matéria de controle de constitucionalidade é dada pelo Legislativo, como ocorre nos sistemas neozelandês, britânico e canadense, mas não se pode dizer que esses sistemas protejam menos os direitos fundamentais que o modelo brasileiro. Aliás, como adiante se mostrará, em pesquisa empírica realizada acerca da jurisdição constitucional brasileira, foi constatado que parcela muito pequena das ações diretas de inconstitucionalidade teve por fundamento a proteção de direitos fundamentais, ou seja, empiricamente, a salvaguarda dos direitos fundamentais não tem sido exatamente o foco do controle concentrado de constitucionalidade realizado pelo STF.

A pesquisa da temática se torna importante na medida em que, embora vários autores já tenham desenvolvido diversas teorias sobre a expansão da jurisdição constitucional ou sobre a necessidade de sua autocontenção, há carência de uma investigação crítico-reflexiva sobre o controle de constitucionalidade à luz das sensibilidade jurídicas brasileiras e sobre como controlar aquele que exerce 0 controle de constucionalidade. Além disso, também é preciso revolver as bases da construção jurídica que enaltece o controle concentrado de constitucionalidade em

\footnotetext{
${ }^{1}$ Frase utilizada pelo Ministro do Supremo Tribunal Federal Joaquim Barbosa durante o julgamento da ação penal n. ${ }^{\circ} 470$ (caso conhecido como processo do "mensalão").

2 Dentre eles, Gilmar Ferreira Mendes, Inocêncio Mártires Coelho e Paulo Gustavo Gonet Branco (2009, p. 1083).
} 
detrimento da tradição brasileira do controle difuso de constitucionalidade.

Para atingir os seus escopos, a pesquisa se desenvolve com base na opção de uma linha crítico-metodológica. Entretanto, a par da perspectiva crítica e reflexiva, a investigação da presente pesquisa não se eximirá de ser jurídicopropositiva, mediante o oferecimento de alternativas ao modelo de controle de constitucionalidade atual.

O presente artigo investiga, inicialmente, as especificidades dos diversos modelos de controle de constitucionalidade, sobretudo no tocante à participação dos Poderes Legislativo e Executivo, o que permitirá mostrar que o sistema de revisão judicial adotado no Brasil não é autoevidente, nem inerente ao constitucionalismo, bem como oferecer perspectivas e alternativas ao modelo brasileiro. Também serão analisados os modelos de controle de constitucionalidade propostos na Assembleia Nacional Constituinte para a Constituição brasileira de 1988 e os debates políticos que foram travados em torno dessa questão. Para que os diversos modelos de controle de constitucionalidade sejam analisados como alternativas - viáveis ou não - à luz do contexto social e político brasileiro, serão aferidas as sensibilidades jurídicas brasileiras, com base no embate entre racionalidade jurídica e legitimidade. A seguir, analisar-se-á o déficit de participação democrática no controle judicial de constitucionalidade. Por fim, serão realizadas reflexões sobre como controlar o controle de constitucionalidade, à luz do contexto brasileiro e das suas instituições. Seguindo a lógica derridiana, neste momento da desconstrução, em que surge uma suspensão angustiante, é que se abre um intervalo de continuidade e se permitem as transformações (DERRIDA, 2010, p. 39).

Portanto, o presente artigo pretende ser um convite à reflexão crítica acerca do controle de constitucionalidade, rompendo com alguns lugares comuns sobre os quais tem se desenvolvido grande parte dos estudos de direito constitucional no Brasil sobre a temática. Nesse contexto, tem-se o objetivo de revolver as próprias bases do controle de constitucionalidade, a fim de que se possam traçar perspectivas e alternativas ao modelo brasileiro.

\section{SISTEMAS JUDICIAIS DE CONTROLE DE CONSTITUCIONALIDADE: ANÁLISE COMPARADA}

Analisar os modelos de controle de constitucionalidade permitirá traçar 
algumas reflexões e alternativas ao sistema brasileiro, com base na sua realidade institucional. Os países que possuem controle de constitucionalidade geralmente adotam uma Constituição rígida, ou seja, que possui hierarquia superior às demais leis e tem um processo mais dificultoso para sua alteração.

O controle judicial abstrato de constitucionalidade surgiu na Áustria, em 1920, com base na proposta de Hans Kelsen. Esse modelo atribui ao Tribunal Constitucional o poder de invalidar, com efeitos gerais e abstratos, determinada lei. Segundo esse sistema, se a Corte Constitucional opta por declarar a invalidade de determinada lei ou dispositivo legal, o Poder Legislativo nada poderá fazer - já que a norma inconstitucional deixa de integrar validamente o ordenamento jurídico -, a não ser editar nova lei com o mesmo conteúdo, que poderá novamente ser derrubada pela Corte Constitucional. De outro lado, se o Tribunal Constitucional declarar a constitucionalidade da lei, ou optar por uma sentença interpretativa, aditiva, substitutiva ou exortativa - quando admitidas tais modalidades de sentença -, o Parlamento poderá se contrapor à decisão judicial para, pela via legislativa, estabelecer um regramento diferente do que foi decidido pela Corte de Justiça (KELSEN, 1942).

O sistema norte-americano de controle de constitucionalidade, por sua vez, permite à Corte Suprema invalidar uma lei somente com efeitos concretos (LINARES, 2008, p. 490). Assim, neste modelo, não se permite que o Judiciário declare a inconstitucionalidade de lei com efeitos erga omnes. Com efeito, inexiste, nos Estados Unidos, o controle concentrado e abstrato de constitucionalidade. Não se olvida que, no sistema norte-americano, há a obrigatoriedade de respeito aos precedentes judiciais da Suprema Corte (staredecisis). No entanto, como o reconhecimento de inconstitucionalidade somente vale para o caso concreto, permite-se, ao menos em tese, que o governo continue aplicando uma lei inconstitucional, o que, todavia, quando levado ao Judiciário, continuará sendo reconhecido como inconstitucional. Assim, o modelo norte-americano, ao menos teoricamente, permite um maior embate institucional entre os Poderes Executivo e Legislativo, de um lado, e o Judiciário, de outro. Entretanto, nos EUA, diante da adoção da força extraordinária dos precedentes, a aplicação, pelo Executivo ou pelo Legislativo, de norma declarada inconstitucional pela Suprema Corte será desestimulada e rechaçada pouco a pouco (LINARES, 2008, pp. 492/493).

De outro lado, alguns países latino-americanos, tais como Bolívia, Colômbia, 
Chile, Equador, Peru, Costa Rica e Guatemala, adotam um sistema de controle de constitucionalidade que permite consulta prévia ao Tribunal Constitucional sobre a constitucionalidade de determinado projeto de lei. Em alguns deles, a manifestação do Tribunal é vinculante para o Parlamento, mas, em outros, não (LINARES, 2008, p. 493).

O sistema constitucional canadense possui uma Carta de Direitos superrígida ou super-majoritária, com um processo extremamente dificultoso para sua alteração. Além disso, adota um modelo de controle de constitucionalidade abstrato, ou seja, com efeitos erga omnes. Entretanto, a Seção 33 da Carta de Direitos e Liberdades do Canadá de 1982 permite que o Parlamento canadense possa aprovar uma lei, com maioria absoluta dos presentes, declarando expressamente que essa lei é válida não obstante os direitos da Carta (notwithstanding a rightincluded in the charter $)^{3}$. Por conseguinte, a lei ou a parte da lei que contém a cláusula notwithstanding será imune ao controle de constitucionalidade pela Corte de Justiça. No sistema canadense, essa cláusulanotwithstanding também poderá ser usada de maneira repressiva. Com efeito, caso o Parlamento não tenha usado a cláusula preventivamente e a Corte de Justiça tenha declarado inconstitucional determinada lei, poderá o Parlamento usar a cláusula notwithstanding e revalidar essa lei. ${ }^{4}$ Assim, no sistema canadense, existe um grande embate interinstitucional, onde 0 Parlamento possui a última palavra em termos de controle de constitucionalidade.

As constituições flexíveis, como já foi exposto, são aquelas cujo processo de alteração não é diferente em relação às demais leis ordinárias. Ao contrário do que é por vezes dito, a existência de uma constituição rígida não é requisito necessário para o controle de constitucionalidade. Como adiante se demonstrará, também é possível a adoção de judicial review em países que possuem constituições flexíveis, embora seja menos frequente.

Em sistemas que adotam constituições flexíveis, há, segundo Sebastián Linares, três possibilidades.

O primeiro modelo é aquele em que textos constitucionais têm a mesma hierarquia de leis ordinárias aprovadas pelo Congresso, e o Poder Judiciário não

\footnotetext{
${ }^{3}$ Carta Canadense de Direitos e Liberdades (Canadian Charter of Rights and Freedoms): "33.(1) Parliament or the legislature of a province may expressly declare in an Act of Parliament or of the legislature, as the case may be, that the Act or a provision thereof shall operate notwithstanding a provision included in section 2 or sections 7 to 15 of this Charter".

${ }^{4}$ Carta Canadense de Direitos e Liberdades (Canadian Charter of Rights and Freedoms): "33. [...] (4)

Parliament or a legislature of a province may re-enact a declaration made under subsection (1)".
} 
tem poder de declarar a inconstitucionalidade dessas leis. Trata-se do sistema conhecido como "modelo de Westminster", que foi adotado durante séculos por países da Common Law. O Reino Unido (até 1998), a Nova Zelândia (até 1999) e o Canadá (até 1982) tiveram esse sistema (LINARES, 2008, pp. 499). Ao contrário do que se poderia pensar, esse modelo não significava o esvaziamento dos direitos individuais. Pelo contrário, no modelo de Westminster, entendia-se que os direitos individuais estavam bem protegidos, na medida em que se asseguravam a todos a igualdade de participação na elaboração das leis. Assim, de acordo com esse sistema, o Parlamento tinha a última palavra em matéria de direitos fundamentais.

O segundo modelo é aquele em que os textos constitucionais, embora possam ser reformados pelo procedimento legislativo comum, possuem maior hierarquia que leis comuns e, além disso, o Poder Judiciário pode exortar o Parlamento a mudar determinada lei considerada incompatível com textos constitucionais. Este sistema, denominado de "exortativo" (hortatory), vige no Reino Unido desde 1998 e na Nova Zelândia desde 1999.

No Reino Unido, em 1998, houve a aprovação do HumanRightsAct. No entanto, de acordo com o modelo adotado, tal Carta de Direitos pode ser modificada pelo mesmo procedimento utilizado para as leis comuns. Além disso, o Poder Judiciário não tem a possibilidade de invalidar as leis promulgadas pelo Parlamento, podendo apenas declarar a sua incompatibilidade frente à Convenção Europeia de Direitos Humanos e a outros Protocolos de Direitos ${ }^{5}$. Essa declaração de incompatibilidade não invalida a lei, mas abre para o Parlamento a possibilidade de revogá-la. ${ }^{6}$ De outro lado, se o Judiciário continuar não aplicando tal lei reconhecida incompatível com a Convenção, passa a haver uma tensão produtiva entre tais Poderes Constituídos. Assim, uma vez reconhecida a incompatibilidade, o Judiciário

\footnotetext{
${ }^{5} \mathrm{O}$ HumanRightsAct do Reino Unido prevê a declaração de incompatibilidade de leis em relação à Convenção Europeia de Direitos Humanos e a outros Protocolos de Direitos, mas não a declaração de incompatibilidade de leis em relação ao próprio HumanRightsAct. $\mathrm{O}$ item 1 da introdução do HumanRightsAct define que os "ConventionRights" protegidos pela Carta são os direitos e liberdades fundamentais previstos nos arts. 2 a 12 da Convenção Europeia de Direitos Humanos, nos arts. $1^{\circ}$ a $3^{\circ}$ do Primeiro Protocolo, no art. $1^{\circ}$ do Trigésimo Terceiro Protocolo e nos arts. 16 a 18 da Convenção Europeia de Direitos Humanos.

${ }^{6}$ HumanRightsAct de 1988: "Section 4. Declaration of incompatibility. [...] (2) If the court is satisfied that the provision is incompatible with a Convention right, it may make a declaration of that incompatibility. [...] (4) If the court is satisfied - (a) that the provision is incompatible with a Convention right, and (b) that (disregarding any possibility of revocation) the primary legislation concerned prevents removal of the incompatibility, it may make a declaration of that incompatibility. [...] (6) A declaration under this section ("a declaration of incompatibility") - (a) does not affect the validity, continuing operation or enforcement of the provision in respect of which it is given; and (b) is not binding on the parties to the proceedings in which it is made."
} 
deverá exortar o Legislativo a revogar a lei incompatível com a Convenção.

Na Nova Zelândia, em 1990, foi editado o New Zealand Bill ofRightsAct, que tinha por objetivo fortalecer o sistema de proteção dos direitos fundamentais, sem, no entanto, retirar a autoridade do Parlamento. Embora não contemplasse textualmente o sistema de declaração de incompatibilidade, em 1999, a Corte Suprema da Nova Zelândia reconheceu para si a possibilidade de declarar a incompatibilidade de lei comum frente à Carta de Direitos, à semelhança do que prevê o HumanRightsActbritânico, de 1998 (LINARES, 2008, p. 504). Assim, a Nova Zelândia também passou a adotar o sistema exortativo.

Por fim, também é possível um modelo em que a constituição flexível, embora não possua um processo de reforma mais dificultoso, tem maior hierarquia que leis comuns, com um modelo de controle de constitucionalidade que permite invalidar leis inconstitucionais. Trata-se do sistema adotado por Israel desde 1994 (LINARES, 2008, p. 499). Esse modelo é semelhante ao que é atualmente aplicável no Reino Unido e na Nova Zelândia, com a diferença de que é possível ao Poder Judiciário reconhecer a inconstitucionalidade e invalidar a lei (LINARES, 2008, p. 506-508).

Assim, fica claro que os modelos de controle difuso e de controle concentrado de constitucionalidade em Cortes Judiciais, com a última palavra em matéria constitucional, não são os únicos sistemas possíveis, tampouco os melhores, nem significa que deixar a decisão final ao Parlamento implica uma menor proteção à Constituição e aos direitos fundamentais.

Após se analisarem os diversos sistemas de controle de constitucionalidade, não se pode, a priori, dizer que um seja melhor que outro em termos de proteção dos direitos fundamentais, sem se analisar o contexto do país que se considera.

Por conseguinte, será importante estudar alguns modelos que foram propostos na Assembleia Nacional Constituinte para a Corte Constitucional brasileira, até que se chegasse à conformação atual.

\section{OS MODELOS DE CONTROLE DE CONSTITUCIONALIDADE PROPOSTOS PARA O BRASIL NA ASSEMBLEIA NACIONAL CONSTITUINTE}

Durante os trabalhos da Assembleia Nacional Constituinte, foram elaboradas 
três principais propostas sobre a estrutura do STF. A primeira delas formulava a criação de um tribunal constitucional ou um tribunal das garantias constitucionais, que seria uma Corte autônoma com a competência exclusiva para decidir questões constitucionais, composta por ministros temporários, ou escolhidos pelo Congresso Nacional, ou, ainda, pelos três Poderes Constituídos. Esse modelo foi defendido por Vivaldo Barbosa (PDT/RJ) na subcomissão do Poder Judiciário e do Ministério Público, com base em proposta formulada pela Ordem dos Advogados do Brasil. Também foi a proposta apresentada na subcomissão dos direitos políticos, dos direitos coletivos e das garantias, pelo relator Lysâneas Maciel (PDT/RJ), com base na formulação de José Paulo Bisol, então relator da comissão da soberania e dos direitos e garantias do homem (KOERNER; FREITAS, 2013, p. 163).

A segunda proposta formulava a criação de uma seção especializada dentro do STF para julgar as questões constitucionais, a qual seria composta por ministros temporários. De acordo com esse modelo, o STF permaneceria com a competência para unificar a jurisprudência acerca da interpretação da legislação federal, mantendo-se com ministros vitalícios (KOERNER; FREITAS, 2013, pp. 163/164). Foi apresentada pela Associação Paulista de Magistrados (APAMAGIS) e defendida na subcomissão por Michel Temer (PMDB/SP), sendo apoiada pelo presidente José Costa (PMDB/AL).

Por fim, a terceira proposta era a de manter o STF com a sua estrutura, composição e forma de escolha dos seus membros, bem como manter a sua competência, permanecendo como tribunal constitucional, federal e de cassação, com ministros vitalícios. Essa tese era defendida por Maurício Corrêa (PDT/DF) e apoiada pelo próprio STF, pela AMB e pelo governo, tendo sido sustentada em audiências públicas pelo ministro Sydney Sanches, pelo jurista Milton dos Santos Martins e pelo então Ministro da Justiça Paulo Brossard (KOERNER; FREITAS, 2013, p. 164).

Nesse contexto, também gerou muita polêmica a discussão sobre os legitimados para a propositura da ação direta de inconstitucionalidade. O governo federal e o STF defendiam que a legitimidade deveria ser mantida com exclusividade ao Procurador Geral da República. A Ordem dos Advogados do Brasil (OAB) e a Associação dos Magistrados Brasileiros (AMB) apoiavam a tese de que a legitimidade deveria pertencer a qualquer cidadão, bastando apenas demonstrar que era titular do direito. Até mesmo os constituintes que eram favoráveis a uma 
manutenção da estrutura e competência do STF defendiam a ampliação da legitimidade ativa (KOERNER; FREITAS, 2013, p. 165). Também havia a proposta de que tribunais superiores e tribunais de justiça pudessem propor a ADI.

Diversas foram as emendas e os destaques de emendas propostos e discutidos sobre essa matéria, sobretudo em relação à composição do STF, às garantias dos seus membros e à competência desse tribunal. Merece relevo o destaque proposto por Nelson Jobim (PMDB/RS) na comissão de sistematização, que pretendia mudar a composição do STF para 16 membros, com mandato de 8 anos, sendo 5 indicados pelo Presidente da República, 6 pela Câmara dos Deputados e 5 pelo próprio STF. Estas últimas vagas seriam reservadas aos magistrados de carreira. Jobim defendia que os ministros do STF deveriam ocupar mandato temporário, ao fundamento de que esse tribunal teria competência para o controle concentrado e o controle difuso de constitucionalidade, enquanto juízes somente seriam vitalícios nos países em que havia apenas controle difuso, como nos Estados Unidos (KOERNER; FREITAS, 2013, p. 169).

A outra proposta pretendia suprimir a competência do STF para uniformização da jurisprudência relativa à interpretação de leis federais.

Os debates na Assembleia Nacional Constituinte foram marcados por intensa polarização política, com a participação de diversos grupos de interesse, sendo retratados como de direita, de centro ou de esquerda.

No tocante ao controle de constitucionalidade, às suas atribuições e ao órgão que deveria exercer esse poder, também houve grande polarização. Os grupos de direita buscavam preservar a competência e a composição do STF, o qual deveria continuar ocupando as funções de Tribunal Supremo e de Corte Constitucional, com poderes para o controle de constitucionalidade, composto por uma magistratura profissional (KOERNER; FREITAS, 2013, pp. 144/145). Os grupos de esquerda propunham que as controvérsias sobre as leis fossem resolvidas pelo Poder Legislativo, por uma delegação deste ou por um tribunal, e que houvesse ampla participação popular no Judiciário (KOERNER; FREITAS, 2013, p. 145). O Supremo Tribunal Federal, como ator político, aliou-se aos grupos de centro e de centro-direita.

Ao final, o STF conseguiu, na maior parte, atingir os seus propósitos, com a permanência de vitaliciedade dos seus ministros, forma de escolha e competência constitucional. Foi criado o Superior Tribunal de Justiça com a competência para 
uniformizar a jurisprudência nacional sobre interpretação de lei federal, função que antes era exercida pelo STF. No tocante à legitimidade para a propositura da ADI, houve uma grande ampliação - ao contrário do que pretendia o STF -, mas não constaram dentre os legitimados os cidadãos, os tribunais de justiça e os tribunais superiores.

A definição do modelo de controle de constitucionalidade adotado pela Constituição Federal de 1988 não pôs fim aos debates em torno da temática, nem no plano normativo, tampouco no plano investigativo e acadêmico. Com efeito, no plano normativo-constitucional, a Emenda Constitucional n.ำ 3/1993 criou a ação declaratória de constitucionalidade e a Emenda Constitucional n.. 45/2004 instituiu a Súmula Vinculante. De outro lado, o avanço da própria postura do STF no exercício do controle de constitucionalidade tem gerado uma nova rediscussão dos limites desse poder e do próprio modelo adotado.

De qualquer forma, não se pode concluir, aprioristicamente, que o sistema de controle judicial de constitucionalidade é melhor que o controle legislativo, como decisão final nessa matéria. Também não se pode afirmar que um modelo de controle judicial de constitucionalidade forte seja preferível a um modelo de controle fraco, que privilegia mais a atividade legislativa. Para uma conclusão a esse respeito, seria preciso analisar as peculiaridades de cada país e de cada modelo, dentro do contexto em que está inserido. Com base nisso, propõe-se, no item seguinte, investigar a sensibilidade jurídica brasileira e a tensão existente entre racionalidade jurídica e legitimidade, à luz do contexto social brasileiro.

\section{CONTROLE DE CONSTITUCIONALIDADE, PATERNALISMO E LEGITIMIDADE: UMA ANÁLISE À LUZ DAS SENSIBILIDADES JURÍDICAS}

No Brasil, há a cultura jurídica de estabelecer o saber jurídico apropriado particularizadamente como fonte de poder e de legitimidade. Nesse sentido, é comum, no meio jurídico e no âmbito judicial, sobrevalorizar a racionalidade jurídica, como fonte para a solução de todos os problemas sociais, em detrimento da legitimidade.

Numa análise antropológica, Roberto Kant de Lima (2009, p. 44), considerando a forma como são resolvidos os conflitos sociais dentro dos processos 
judiciais, faz uma diferenciação entre as sensibilidades jurídicas - que também chama de sentidos de justiça ou descoberta da verdade - nos EUA e no Brasil. A esse respeito, mostra como, no sistema americano, o estabelecimento da verdade, o controle social e a solução dos conflitos ocorrem, dentro do processo, pela lógica adversária, que atribui valor ao saber local, à argumentação, ao entendimento e ao convencimento, onde a decisão das partes prevalece sobre a autoridade do Estado na solução dos conflitos, pois o consenso das partes legitima a decisão. No Brasil, ao contrário, prevalece, no processo, a lógica do contraditório, do dissenso infinito; há a sobreposição do interesse público sobre o privado; existe uma confusão entre os interesses públicos - atribuídos ao Estado e aos seus funcionários -, e os interesses da sociedade, do público em geral. Por conseguinte, no sistema institucional brasileiro, os saberes particulares e especializados são sinônimos de poder e não precisam do consenso, pois o consenso não legitima, sendo que a legitimidade da decisão estatal é oriunda do saber especializado e particularizado de uma autoridade. Assim, Roberto Kant de Lima (2009, p. 44) afirma que, no Brasil, a sensibilidade jurídica é de que os funcionários públicos, em nome do interesse público, poderiam substituir os interesses dos hipossuficientes, ou seja, dos cidadãos que não conhecem os seus direitos e, por isso, não poderiam exercitá-los. Por conseguinte, conclui que, no Brasil, "a legitimação se dá por um saber particularizado, pertencente a uma elite que reivindica seu poder de decisão sobre a sociedade, através de seu pertencimento e de sua fusão com o Estado: é a Ruleby Law', em uma contraposição que o autor faz ao Ruleof Law que existiria nos EUA.

Diferentemente do que ocorre nos processos de tomadas de decisão política do parlamento, em que prevalece a lógica adversária, no âmbito judicial brasileiro a lógica é contraditória, em que o saber particularizado se converte em poder público. $\mathrm{Na}$ seara legislativa, ao contrário, utilizam-se as formas de convencimento, de entendimento e de persuasão pela argumentação. No Judiciário, existe uma lógica desigual entre os interlocutores, em que prevalecerá o argumento de autoridade, pois o julgador ouve os argumentos das partes, mas é ele quem decide, não precisando convencê-las pelo seu argumento, pois ele é "melhor" porque detém autoridade, porque possui um conhecimento especializado, porque o juiz, como terceiro e imparcial, está em melhores condições de dizer qual parte possui razão. Nesse sentido, no Judiciário brasileiro, mesmo as decisões colegiadas obedecem a esse modelo, pois são tomadas por contagem de votos, e não pelo consenso entre 
os seus membros. ${ }^{7}$

No entanto, será que a sensibilidade jurídica brasileira seria a de confiar mais nas decisões do Judiciário do que nas decisões do Legislativo? Os cidadãos brasileiros confiam nas suas instituições? A perspectiva que outorga mais poderes à racionalidade jurídica é uma sensibilidade jurídica dos cidadãos, ou dos juristas brasileiros?

É preciso ressaltar que, muitas vezes, esse modelo de sobrevalorização da racionalidade jurídica por parte de algumas instituições estatais cria uma oposição entre os interesses públicos - do Estado ou dos seus funcionários - e os interesses da sociedade. Surge $o$ argumento de que a sociedade, por não deter o conhecimento particularizado dos operadores do direito, não tem condições de decidir por si própria. As "pessoas leigas", "hipossuficientes no sentido técnicojurídico", não estariam aptas a tomar as suas próprias decisões, precisando que o Estado tutele seus interesses (LIMA, 2009, pp. 43/44). A partir disso, é comum ouvir entre juristas e constitucionalistas brasileiros que o povo teria voluntariamente delegado ao Judiciário o controle de constitucionalidade e a proteção dos direitos humanos, por ter conhecimentos técnico-jurídicos que lhe permite a melhor decisão em matéria de interpretação e aplicação da Constituição e das leis.

Nesse tocante, sob uma perspectiva realista, não se trata da proteção realizada pela Corte Constitucional contra o arbítrio do Poder Legislativo, sob a acusação de que este seria capaz de sufragar o direito das minorias em benefício das maiorias. O Poder Legislativo também realiza controle de constitucionalidade ao debater, votar e aprovar um projeto de lei. O controle abstrato de constitucionalidade realizado pela Corte Constitucional é, pragmaticamente, a sobreposição da sua interpretação (ato de vontade) em detrimento da interpretação constitucional realizada pelo Parlamento. Vale dizer, é a sobreposição da decisão "jurídica" da Corte Constitucional sobre a decisão "política" do Parlamento. Mas o que levaria um país a adotar um modelo institucional que outorga à racionalidade jurídica da Corte Constitucional o poder de se sobrepor (pelo controle de constitucionalidade) à

\footnotetext{
7 Roberto Kant de Lima (2009, pp. 43/44) fez um importante estudo na perspectiva comparada entre os sistemas judiciais brasileiro e estadunidense. Nessa pesquisa, mostra como a lógica do sistema judicial brasileiro é contraditória, enquanto, no sistema judicial estadunidense, é adversária. Sob o modelo do trialbyjury, nos EUA até mesmo os tipos penais são negociados entre as partes e, caso o cidadão não concorde com o tipo penal que lhe é imposto, pode pedir que a acusação penal ou cível seja submetida ao júri, no qual (também diferentemente do Brasil), seus pares (cidadãos) o julgarão por uma decisão consensuada (e não pela soma dos votos).
} 
legitimidade do Parlamento? Por que se difundiu entre constitucionalistas brasileiros a sabedoria convencional de que o controle judicial de constitucionalidade é um desdobramento necessário da ideia central de constitucionalismo e de força normativa da Constituição? Quais circunstâncias levariam a concluir que os discursos judiciais de aplicação do direito seriam melhores que os discursos de justificação ${ }^{8}$ dos parlamentos? Por que racionalidade jurídica seria melhor que legitimidade?

Como já se expôs, existe um forte componente político e institucional que leva alguns países a adotar o modelo de controle judicial (e não legislativo) como decisão final sobre a constitucionalidade. Mas, além disso, também parece haver um elemento irracional, um ato de fé em determinadas instituições em detrimento de outras, um fundamento místico que leva a acreditar que a decisão da Corte Constitucional é melhor ou mais legítima que a decisão política do parlamento.

Quando determinada lei aprovada pelo parlamento é submetida à revisão judicial, o debate público sobre direitos e sobre a escolha política se reduz a um debate sobre tecnicismo jurídico entre os membros da Corte Constitucional, mascarando por vezes uma escolha política ou moral dos julgadores. Então, ao menos em abstrato, parece não haver boas razões para confiar mais na escolha da "melhor interpretação" pelos juízes do Tribunal Constitucional do que na escolha política e moral explícita do parlamento, composta por diversos membros.

Analisando a realidade brasileira, Juliano Zaiden Benvindo (2011) constata que o constitucionalismo brasileiro está se incrementando em termos de racionalidade jurídica, mas se enfraquecendo em termos de legitimidade. $\mathrm{O}$ autor conclui que, "sem limites, há o contínuo risco do monólogo e da construção arbitrária do conteúdo decisório, o que é um sério ataque à democracia constitucional" (BENVINDO, 2011). Entretanto, talvez o sistema judicial brasileiro e o controle judicial de constitucionalidade se incrementem em termos de racionalidade jurídica sem que essa seja uma opção da sociedade. A esse respeito, é preciso indagar se a sensibilidade jurídica que confia mais nos saberes apropriados particularizadamente é dos juristas ou da sociedade em geral.

Em pesquisa de campo realizada no primeiro semestre de 2017 , constatouse que os brasileiros confiam pouco nas suas instituições em geral e,

\footnotetext{
8 Discursos de justificação são aqueles que devem preceder à elaboração da norma, e os discursos de aplicação são os que devem nortear a atividade judicial.
} 
especificamente, nos partidos políticos, nas instituições legislativas e no Judiciário. $\mathrm{Na}$ declaração espontânea, apenas $24 \%$ da população afirmaram que confiam no Poder Judiciário. De outro lado, a confiança nas instituições parlamentares é ainda menor, pois a pesquisa mostrou que apenas $7 \%$ dos entrevistados confiam no Congresso Nacional e também somente $7 \%$ nos partidos políticos (FUNDAÇÃO GETÚLIO VARGAS, 2019). Além disso, outras pesquisas de campo demonstraram que, em questões polêmicas como a admissão de união estável entre casais homoafetivos $^{9}$ e a legalização das drogas $^{10}$, a maioria da população (dos entrevistados) entende que tais matérias devem ser decididas pelos próprios cidadãos, via plebiscito, e não pelos Poderes Judiciário, Legislativo e Executivo.

Sem desconsiderar as inúmeras circunstâncias que podem interferir nas respostas, uma leitura possível desses dados pode levar a concluir que as pessoas pretendem participar mais dos processos de tomada de decisão, decidindo diretamente as questões políticas ou constitucionais que envolvem alguma polêmica e que atingem toda a coletividade. Isto é, o povo tem vontade de Constituição, de participar da tomada de decisão sobre questões polêmicas, de estar inserido no projeto constitucional. Isso talvez coloque em xeque a afirmação de que a sensibilidade jurídica brasileira seria de privilegiar a racionalidade jurídica em detrimento da legitimidade. Ou melhor, talvez essa supervalorização da racionalidade jurídica seja uma perspectiva dos juristas, mas não dos cidadãos brasileiros.

Aliás, talvez não seja verdadeira a premissa de que os cidadãos preferem confiar decisões políticas aos Poderes Constituídos a tomar eles próprios as suas decisões sobre as questões que envolvem toda a população e os rumos da nação.

\footnotetext{
9 "Indagados sobre a quem deveria caber a decisão em casos como este, $40 \%$ dos entrevistados apontam a própria população, via plebiscito. Na sequência, o mais legitimado para decidir seria o STF, indicado por $24 \%$ dos entrevistados. Sendo que, entre os que conhecem o STF, ele é o mais citado como principal responsável para esse tipo de decisão ( $41 \%$ das menções para o STF frente a $30 \%$ para plebiscito). Não podemos, pois, afirmar que existe uma percepção social de que o STF está interferindo com competências do Poder Legislativo. [...] O terceiro colocado, no que concerne à responsabilidade para este tipo de decisão, é o Legislativo, com $18 \%$ das indicações e, por último, aparece o Executivo, com $11 \%$. Os dados mostram que, entre os Poderes instituídos, o Judiciário, via STF, é quem goza de maior legitimidade decisória para casos com esse teor". (FALCÃO, 2013, pp. 457/458).

10 "Na opinião de $39 \%$ dos entrevistados que acompanharam a decisão do STF sobre a marcha da maconha, a decisão sobre a legalização das drogas deveria se dar via plebiscito. Em segundo lugar, como o mais legitimado a decidir sobre legalização das drogas aparece o STF, com $19 \%$ das menções, tecnicamente empatado com o Legislativo, com 18\%. E, por fim, o Executivo, com $13 \%$ das menções. Outra vez, nesse caso, não podemos afirmar se existe a percepção de interferência, ainda que legítima, do STF no âmbito do Congresso Nacional." (FALCÃO, 2013, pp. 462/463)
} 
Esta pode até ser uma visão dos juristas sobre a população, mas talvez não seja uma visão do povo sobre os juristas e sobre a racionalidade jurídica.

Além disso, a referida pesquisa de campo demonstrou que parcela significativa preferiu confiar decisões dessa natureza ao STF ou ao Legislativo, sendo que a menor parte (mas não irrisória) preferiria confiar na decisão do Poder Executivo. Ao se internalizarem essas divergências, esses dados podem indicar que os cidadãos pretendem ter maior participação direta no processo de tomada de decisão sobre questões polêmicas, mas sem excluir a participação das demais instituições, sobretudo dos Poderes Judiciário, Legislativo e Executivo.

Isso traz diversas inquietações em relação ao atual modelo de tomada de decisões e, inclusive, em relação ao judicial review, deixando latentes algumas questões: No controle de constitucionalidade, haveria mecanismos para promover uma redução do déficit democrático do controle de constitucionalidade ao invés de aceitar a submissão à racionalidade jurídica solipsista e paternalista do Supremo Tribunal Federal? Como pensar em formas de permitir uma maior participação dos cidadãos e de outras instituições públicas e privadas, além dos Poderes Executivo, Legislativo e Judiciário? Como o povo poderia influenciar e controlar o processo de tomada de decisão do Supremo Tribunal Federal no controle de constitucionalidade?

\section{O DÉFICIT DE LEGITIMIDADE E DE PARTICIPAÇÃO DEMOCRÁTICA NO CONTROLE ABSTRATO DE CONSTITUCIONALIDADE}

Um estudo adequado do controle de constitucionalidade pressupõe a análise institucional do país que se considera. Desse modo, a importação de teorias e perspectivas estrangeiras sem considerar a realidade institucional interna não é capaz de dar soluções adequadas para a problematização do controle de constitucionalidade no Brasil. A esse respeito, Cass Sunstein e Adrian Vermeule (2003, pp. 885-886) criticam as teorias que debatem as questões interpretativas em altos níveis de abstração em termos de democracia, legitimidade e autoridade da Constituição, mas não são capazes de resolver problemas práticos; em contraste, entendem que é mais promissor focar em dois aspectos negligenciados, quais sejam, a capacidade das instituições e os efeitos dinâmicos produzidos na esfera pública e particular.

Como já foi salientado, é perceptível um expansionismo do Poder Judiciário 
brasileiro em termos institucionais, que passa cada vez mais a ocupar espaços que antes eram de exclusividade dos Poderes Executivo e Legislativo. Entretanto, ao enfrentar o debate sobre o sistema de freios e contrapesos, não se pode deixar de analisar a realidade das instituições, bem como os resultados práticos do desempenho das suas funções. Descurar da questão empírica pode significar naufragar em elucubrações metafísicas com resultados totalmente indesejáveis, sobretudo do ponto de vista democrático.

Nos países em que o Legislativo se apresenta através de um órgão com mais problemas de corrupção ou mais burocrático, e a sociedade civil tem menos capacidade de mobilização, talvez seja mais fácil justificar a presença de um Judiciário mais ativista. Todavia, o problema é que, nesses casos, a proatividade judicial talvez impeça que a própria sociedade se mobilize e que o Legislativo corrija os seus problemas. Assim, ao invés de decidir pelo Legislativo, talvez seja mais produtivo que o Judiciário atue com uma postura de apenas corrigir aspectos pontuais, problemas de corrupção ou inerentes ao processo legislativo, mas deixe que o Parlamento decida politicamente a questão substancial.

Outra temática que merece ser analisada à luz da realidade institucional concreta é o déficit democrático do controle de constitucionalidade. Nesse aspecto, o controle difuso e concreto de constitucionalidade, realizado de forma incidental em determinado processo, cuja decisão atinge apenas as partes que dele participaram, não parece ser tão problemático do ponto de vista da legitimidade democrática.

De outro lado, no procedimento das ações de controle abstrato de constitucionalidade, realizado no Supremo Tribunal Federal, observa-se que a ausência de participação daqueles que serão atingidos pela decisão é um traço marcante. Com efeito, a ação direta de inconstitucionalidade - principal ação do controle abstrato - têm apenas um reduzido rol de legitimados ativos. Se isso não bastasse, embora o art. 103, § $3^{\circ}$, da Constituição Federal estabeleça que o Advogado-Geral da União está obrigado a defender a constitucionalidade da lei impugnada, por diversas vezes, o interesse do governo federal é a declaração de inconstitucionalidade da lei ou do ato normativo impugnado, razão pela qual, nesses casos, não haverá defesa da lei e, por conseguinte, inexistirá contraditório efetivo. Foi o que aconteceu, por exemplo, no processo da Ação Direta de Inconstitucionalidade $\mathrm{n} .94 .424$, proposta contra os artigos 12, inciso I, e 16, ambos da Lei no 11.340/2006 (Lei Maria da Penha). Assim, uma lei elaborada 
democraticamente e que obedeceu ao processo legislativo de formação, com ampla participação dos representantes do povo, com a consideração de todos os argumentos e opiniões dos parlamentares, poderá ser declarada inconstitucional sem que haja qualquer defesa da sua constitucionalidade.

Se isso não bastasse, o déficit democrático do controle concentrado de constitucionalidade também é marcante na fase decisória. Com efeito, nos julgamentos realizados pelo Supremo Tribunal Federal de ações do controle abstrato e concentrado de constitucionalidade, não há propriamente um debate entre os seus membros, pois cada um deles vai para a sessão plenária com um voto pronto, ocorrendo comumente apenas a sua leitura e uma singular contagem dos votos individuais. Com efeito, pesquisa empírica demonstrou que a grande maioria dos votos dos Ministros do STF nos julgamentos colegiados (cerca de 80,30\%) não possui qualquer consideração aos argumentos dos seus pares (KLAFKE, 2010, p. 119). Assim, um voto mais fundamentado, com pesquisa empírica e análise profícua da complexidade da matéria que está sendo julgada tem o mesmo peso de um voto com fundamentação rasa, ou que apenas acompanha o relator ou a divergência. Por conseguinte, cada Ministro seleciona um número limitado de perspectivas e dificilmente se deixa influenciar pelas perspectivas do outro. Nesse sentido, do ponto de vista da absorção da diversidade e da reflexividade de cada argumento, o processo decisório do Supremo Tribunal Federal é bastante limitado.

Isso se agrava quando se observa que, em aproximadamente 1/3 dos julgamentos do STF em ações do controle abstrato, as decisões são tomadas por maioria, ou seja, com divergência entre os Ministros (SUNDFELD; SOUZA, 2012, pp. 75-116. p. 85). Vale dizer, em grande parte dos julgamentos do STF, há divergência entre os seus membros, mas o processo decisório não comporta uma verdadeira forma de internalização dessas divergências.

Se esse procedimento decisório for comparado a uma lei editada pelo parlamento, o déficit democrático do controle concentrado se mostra ainda mais grave. Para que uma lei federal entre em vigor no Brasil, é necessário que seja aprovada por maioria na Câmara dos Deputados, que conta com 513 deputados federais, e no Senado Federal, que possui 81 senadores. Em cada uma dessas casas legislativas, o projeto de lei precisa ser discutido e aprovado pelas comissões de constituição e justiça e pelas comissões temáticas, sendo que, somente após, será levado ao plenário da respectiva Casa. Além disso, após a ampla discussão e a 
sua aprovação pelas duas Casas Legislativas, ainda é necessário que o projeto de lei seja sancionado pelo Presidente da República. Não obstante esse longo processo legislativo, em contrapartida, basta uma maioria de 6 votos a 5 no Supremo Tribunal Federal para que a lei seja declarada inconstitucional.

Portanto, observa-se que o controle concentrado de inconstitucionalidade possui um grande déficit de legitimidade, seja em relação aos legitimados ativos e passivos do processo, seja no concernente ao processo decisório.

A par da discussão teórica acerca dos graves problemas inerentes ao procedimento das ações do controle concentrado, mister ilustrar como isso tem sido devastador do ponto de vista pragmático.

Aqui, é importante retomar o caso do julgamento da ADI 4.424, proposta contra a Lei Maria da Penha, que foi exposto no primeiro capítulo. O Projeto de Lei 4.559/2004, que deu origem à Lei Maria da Penha (Lei no 11.340/2006), foi elaborado pelo Grupo de Trabalho Interministerial formado por pelo menos oito órgãos do Poder Executivo Federal, inclusive os mais importantes dentro da sua estrutura (CÂMARA DOS DEPUTADOS, 2019). Além disso, participaram da elaboração do referido projeto o Consórcio de Organizações Não-Governamentais Feministas, sendo amplamente discutido com representantes da sociedade civil e órgãos diretamente envolvidos na temática. $O$ referido projeto também foi objeto de diversas oitivas, debates, seminários e oficinas (CÂMARA DOS DEPUTADOS, 2019). Por fim, foi debatido exaustivamente por diversas comissões da Câmara dos Deputados e do Senado Federal (SENADO FEDERAL, 2019, pp. 4-7), sendo aprovado em ambas as Casas Legislativas e sancionado pelo Presidente da República. Todavia, o STF, mediante a votação de apenas 11 Ministros - restando, ainda, vencido o Presidente Ministro Cezar Peluso -, declarou inconstitucional dispositivos da Lei Maria da Penha. Isso, por si só, já denota que é muito limitada a capacidade institucional do STF, no controle abstrato e concentrado de constitucionalidade, para assumir todas as expectativas e perspectivas dos atingidos pela decisão e das instituições judiciais e não-judiciais que atuam na prevenção e repressão ao combate da violência doméstica. Caso se considere que os atores que participam do processo do controle abstrato de constitucionalidade (ProcuradorGeral da República, Advogado-Geral da União etc.) sequer participam dos processos judiciais individuais que tratam da violência doméstica, fica ainda mais evidente a ausência da capacidade institucional do controle abstrato e concentrado 
de constitucionalidade para dar uma resposta adequada para a questão, ou que permita a participação democrática.

Ademais, pesquisa empírica demonstrou que, considerando os 267 acórdãos do STF proferidos em controle concentrado de constitucionalidade entre junho de 2006 a janeiro de 2010, apenas $2 \%$ dos votos dos Ministros do STF fizeram alguma menção ao histórico legislativo das leis impugnadas (SUNDFELD, 2012, pp. 90/91). Isso quer dizer que, pragmaticamente, o STF não costuma considerar o debate institucional e popular que dá origem à lei objeto do controle abstrato de constitucionalidade.

De outro lado, o controle concentrado e abstrato de constitucionalidade no Brasil, pelas suas peculiaridades, também proporciona um considerável desequilíbrio federativo. Com efeito, nesse modelo de controle, realizado pelo Supremo Tribunal Federal, os Estados-membros não tem oportunidade de se manifestar ou, ao menos, essa oportunidade é muito limitada. De um lado, é verdade que a Constituição Federal (art. 103) autoriza a Mesa de Assembleia Legislativa ou da Câmara Legislativa do Distrito Federal e o Governador de Estado ou do Distrito Federal a propor ações do controle concentrado de constitucionalidade. Também é verdade que, caso seja impugnada uma lei ou um ato normativo estadual, o órgão estadual responsável pela sua edição será intimado para prestar informações. No entanto, caso a controvérsia verse sobre a competência estadual ou federal para legislar sobre determinada matéria, e seja proposta uma ação declaratória de constitucionalidade sobre determinada lei federal, não haverá manifestação de órgãos estaduais.

Além disso, caso algum legitimado diverso dos entes estaduais proponha ação direta de inconstitucionalidade em face de determinada lei ou ato normativo estadual, a defesa do ato impugnado será realizada pela Advocacia-Geral da União, apenas com prestação de informações pelo órgão estadual, parecer do ProcuradorGeral da República e julgamento pelo Supremo Tribunal Federal. Assim, neste caso, também há um desequilíbrio federativo, pois o órgão estadual apenas poderá prestar informações sobre a edição da lei. Nem é preciso dizer que, em caso de interesse federal, a Advocacia-Geral da União não apresentará defesa da lei ou do ato normativo estadual. Além disso, mesmo que se considerasse a prestação de informações do órgão estadual uma defesa, é intuitivo que o peso das manifestações dos entes federais (Advocacia-Geral da União e Procuradoria-Geral 
da República), que sempre participam do processo de controle de constitucionalidade, é muito maior.

Portanto, o controle de constitucionalidade apresenta muitos problemas do ponto de vista de legitimidade democrática e também sob a perspectiva do equilíbrio federativo. Mas é preciso perquirir se esses problemas são ou não compensados por outras vantagens.

A esse respeito, é comum a afirmação de que o controle abstrato e concentrado de constitucionalidade tem servido para a proteção dos direitos fundamentais, inclusive sendo um mecanismo para salvaguardar os direitos das minorias contra a "tirania da maioria", uma contingência da democracia. Entretanto, consoante já salientado, pesquisa empírica realizada sobre a jurisdição constitucional do STF demonstrou que, entre os anos de 2000 e 2008, apenas 11\% das decisões de procedência em sede de ações diretas de inconstitucionalidade mencionaram a proteção de direitos fundamentais, além do que, dentre elas (11\%), $60 \%$ eram, na verdade, decisões em prol de interesses corporativos (BENVINDO, 2014). Isso comprova empiricamente que os direitos fundamentais não têm sido o principal foco do STF no controle abstrato de constitucionalidade e que podem estar sendo usados desvirtuadamente como fundamento para defesa de outros interesses. Portanto, a justificativa de proteção de direitos fundamentais não é empiricamente válida para sustentar o controle concentrado e abstrato de constitucionalidade em detrimento da legitimidade democrática e do equilíbrio federativo.

De outro lado, tais problemas levantados em relação a esse modelo talvez não atinjam o controle difuso e concreto de constitucionalidade, ou, ao menos, talvez não o atinjam na mesma medida. Talvez a importância do controle difuso e concreto esteja sendo subestimada na realidade institucional brasileira, pois parece ser qualitativamente superior ao controle abstrato e concentrado.

Alguns constitucionalistas como Gilmar Ferreira Mendes, Inocêncio Mártires Coelho, Paulo Gustavo Gonet Branco (2009, p. 1104) sustentam que "a Constituição de 1988 reduziu o significado do controle de constitucionalidade incidental ou difuso ao ampliar, de forma marcante, a legitimação para propositura da ação direta de inconstitucionalidade (art. 103) [...]". Também afirmam que isso permitiu que "[...] praticamente, todas as controvérsias constitucionais relevantes sejam submetidas ao Supremo Tribunal Federal mediante processo de controle abstrato de normas". 
Entretanto, os dados estatísticos acerca dos processos que tramitam no STF demonstram exatamente o contrário.

Com efeito, dos 36.315 processos que tramitavam no STF até 21/6/2019, apenas 2.192 veiculam ações do controle concentrado $\mathrm{e}$ abstrato de constitucionalidade, ou seja, o controle concentrado e abstrato de constitucionalidade ocorre em apenas $6,03 \%$ dos processos que atualmente (21/6/2019) compõem o acervo do STF (SUPREMO TRIBUNAL FEDERAL, 2019).

Esses dados mostram que não se pode dizer que o controle concreto de constitucionalidade tenha perdido importância, ou que tenha deixado de ocupar a pauta do STF. Pelo contrário, o controle difuso e concreto continuou sendo, mesmo após a Constituição Federal de 1988, o principal mecanismo de controle judicial de constitucionalidade, ao menos em termos numéricos.

Além disso, também se deveria levar em consideração que diversas questões constitucionais são decididas pelas instâncias judiciais inferiores e não chegam à Suprema Corte. Com efeito, no Judiciário brasileiro, tramitam mais de $\mathrm{R} \$$ 80,1 milhões de processos (CONSELHO NACIONAL DE JUSTIÇA, 2019, p. 197), em que pode ser realizado o controle difuso de constitucionalidade. Com efeito, a cada aplicação do direito ao caso concreto, os juízes incidentalmente analisam a constitucionalidade dos atos normativos infraconstitucionais, ou garantem a aplicação direta dos dispositivos constitucionais.

Portanto, considerando somente as ações que tramitam no Supremo Tribunal Federal, constata-se que o quantitativo de processos que tem por objeto 0 controle abstrato e concentrado de constitucionalidade é proporcionalmente bastante baixo, se comparado com a quantidade de ações em que ocorre o controle concreto e difuso de constitucionalidade. Caso se considerem todos os processos que tramitam nas demais instâncias judiciais, constatar-se-á que o percentual de processos em que há controle abstrato no STF passa a ser irrisório, ao menos em termos quantitativos. É claro que, numa ação do controle abstrato no STF, a sentença produz efeitos para todos. Mas não é menos verdade que o entendimento do STF exposto numa ação do controle difuso também serve de paradigma para que as demais instâncias judiciais sigam tal decisão.

De qualquer forma, parece que o controle difuso e concreto não perdeu a sua importância em detrimento do controle abstrato de constitucionalidade. Pelo contrário, atualmente permanece tendo o lugar central que tradicionalmente ocupava 
mesmo antes da Constituição Federal de 1988. De outro lado, se os constitucionalistas não têm dado a merecida atenção ao controle difuso, isso é outra questão.

\section{QUEM CONTROLA O CONTROLADOR?}

Como já foi exposto, para aferir os modelos de controle de constitucionalidade e chegar a alguma conclusão sobre aquele que melhor atenda aos critérios de legitimidade democrática e de aptidão para a proteção dos direitos fundamentais, é preciso analisar a capacidade institucional e a realidade política de cada país. De outro lado, é certo que conferir o poder de controlar a constitucionalidade ao órgão mais representativo ou ao mais imparcial não seria capaz, por si só, de garantir decisões corretas e justas. Da mesma forma, seria ilusório acreditar num arranjo político-institucional de controle de constitucionalidade que seja indene de máculas, incorruptível ou cujas decisões sejam sempre sinônimos de justiça. Assim, tão importante quanto definir alguma autoridade ou órgão dentro da estrutura estatal para decidir o sentido do texto constitucional é estabelecer os mecanismos institucionais de controle desse poder. Em outras palavras, é necessário perquirir: Quem controla o controlador? ${ }^{11}$

Comparando-se os diversos modelos constitucionais, é possível constatar que geralmente há algum controle interinstitucional ou popular exercido sobre o órgão responsável por exercer o controle de constitucionalidade.

Como já se expôs, a Carta de Direitos e Liberdades do Canadá, na Seção 33, permite que o seu Parlamento possa aprovar uma lei, com maioria absoluta dos presentes, declarando expressamente que essa lei é válida não obstante os direitos da Carta (notwithstanding a rightincluded in the charter), ou seja, admite que esta lei ou parte dela não se sujeite à revisão judicial. Além disso, poderá o Parlamento canadense usar a cláusula notwithstanding para revalidar uma lei declarada inconstitucional pelo Judiciário (LINARES, 2008, p. 494-496). Assim, no modelo constitucional canadense, o Poder Legislativo controla o controlador, ou seja, tem o poder de revisar uma decisão judicial do controle de constitucionalidade.

No Reino Unido, o Poder Judiciário não tem a possibilidade de invalidar as

\footnotetext{
11 Essa é a pergunta que orienta grande parte da obra "O futuro da democracia", de Norberto Bobbio (2000, p. 43).
} 
leis promulgadas pelo Parlamento, podendo apenas declarar a sua incompatibilidade frente à Convenção Europeia de Direitos Humanos e exortar o Legislativo a revogar a lei incompatível. Todavia, o Judiciário poderá continuar não aplicando tal lei reconhecida incompatível com a Convenção, o que gera uma tensão produtiva entre tais Poderes Constituídos. Assim, de um lado, nos casos concretos judicializados, o Poder Judiciário dá a última palavra em termos de controle de constitucionalidade; de outro lado, em geral e em abstrato, o Legislativo continua tendo a decisão final em termos de controle de constitucionalidade, pois a lei declarada judicialmente incompatível com a Convenção continua tendo vigência e validade no sistema jurídico enquanto o parlamento não se manifestar sobre isso.

No Brasil, houve uma opção política, expressamente inserida na Constituição Federal, de que o Judiciário realizaria o controle de constitucionalidade de leis e atos normativos, seja no controle difuso, seja no controle concentrado. Assim, em princípio, estaria conferindo ao Judiciário o poder de decidir por último. Entretanto, caberia perquirir: Quais seriam os mecanismos institucionais para garantir a supremacia da Constituição, ao invés da supremacia da Corte Constitucional? Isto é, como garantir a supremacia da Constituição, mas não a supremacia da Corte Constitucional sobre os demais Poderes Constituídos e sobre a própria Constituição? Haveria como pensar em controle de constitucionalidade e, ao mesmo tempo, garantir que o direito não seja simplesmente aquilo que onze membros da Corte Constitucional querem que ele seja? Enfim, existiriam mecanismos para que os cidadãos, a sociedade civil organizada e as instituições pudessem controlar o controle judicial de constitucionalidade?

Para buscar uma alternativa viável e mais democrática, Conrado Hübner Mendes (2008, pp. 161-171) propõe que, no Brasil, o controle de constitucionalidade deve efetivamente ser realizado pelo Judiciário, mas que a palavra final deveria ficar com o Poder Legislativo, mediante o mecanismo da emenda constitucional. Para sustentar isso, afirma que não há qualquer dispositivo na Constituição Federal que permita o controle judicial de constitucionalidade de emendas constitucionais.

Com efeito, a definição sobre a possibilidade de revisão judicial de emenda constitucional ocorreu em 1993, a partir da decisão do STF no julgamento da medida cautelar da Ação Direta de Inconstitucionalidade n. 926 (SUPREMO TRIBUNAL FEDERAL, 1993, p. 85), mas esse poder judicial não está expresso na Constituição Federal, e é altamente questionável. Assim, se fosse vedado o controle de emendas 
constitucionais, quando o STF entendesse que determinada lei é inconstitucional, poderia o Congresso Nacional, mediante o mecanismo de emenda constitucional, fazer prevalecer a decisão legislativa sobre a decisão judicial, vale dizer, o Legislativo daria a última palavra em termos de controle de constitucionalidade.

Aliás, nos Estados Unidos, a Suprema Corte não pode exercer a revisão judicial das emendas constitucionais. Em contraponto, o processo de edição de emendas constitucionais nos EUA é extremamente dificultoso, o que torna mais laboriosa a possibilidade de derrubada de uma decisão judicial pelo Legislativo norte-americano.

No Brasil, ao revés, o processo de edição de emendas constitucionais é bem mais facilitado, embora tenha um procedimento mais dificultoso que o exigido para os demais atos normativos. De um lado, uma emenda constitucional exige aprovação, em 2 turnos de votação, pelo quórum qualificado de 3/5 dos membros de cada casa legislativa (art. 60, $\S 2^{\circ}, \mathrm{CF}$ ). No entanto, quando existe consenso entre a maioria, esse processo tem um tramitar muito rápido. Tanto é que, no Brasil, até 21.6.2019, com pouco mais de 30 anos da Constituição Federal de 1988, já haviam sido editadas 99 emendas constitucionais, além das 6 emendas constitucionais de revisão. Apenas para fazer uma comparação, até a mesma data, em 232 anos da Constituição dos EUA (de 1787), houve apenas 27 emendas.

Considerando o direito comparado, não haveria nenhuma novidade caso se admitisse, no Brasil, a possibilidade de que o Legislativo, através do mecanismo de emenda, desse a última palavra em matéria constitucional. Além dos EUA, o sistema canadense também não admite o controle de emendas constitucionais. Isso, no entanto, não quer dizer que, considerando a realidade institucional brasileira, deixar ao Legislativo a decisão final em termos de controle de constitucionalidade seja a melhor opção.

Nesse aspecto, poder-se-ia afirmar que, do ponto de vista da possibilidade de controle do controlador, o Legislativo tem de prestar contas ao povo (accountability) e, assim, os cidadãos poderiam exercer pressão para mudar uma decisão tomada pelo parlamento em controle de constitucionalidade. Por conseguinte, num plano ideal, outorgar ao Legislativo o poder de controlar o controle judicial de constitucionalidade, é uma alternativa. Entretanto, se essa alternativa seria viável no Brasil, ou se seria a melhor, é absolutamente questionável. Essa é uma reflexão que deve permanecer sempre em aberto. 
De outro lado, mesmo que se possa eleger uma instituição como sendo a melhor para dar a decisão final em matéria de controle de constitucionalidade, essa instituição sempre poderá tomar uma decisão equivocada. Considerando a complexidade e as contingências inerentes a qualquer modelo de controle, será preciso perquirir qual será a forma institucional utilizada para corrigir esses erros ou distorções cometidas pelo controlador.

No Brasil, como já exposto, há um entendimento bastante consolidado de que a palavra final em termos de controle de constitucionalidade é do Judiciário, bem como que é possível o controle judicial de emendas constitucionais. Caso se assumisse essa premissa como verdadeira e seja levado em consideração que o Judiciário pode tomar uma decisão equivocada, caberia questionar quais seriam os mecanismos para que esse erro possa ser corrigido.

Quando se analisa o modelo de controle abstrato e concentrado de constitucionalidade adotado no Brasil, a resposta para essa indagação talvez seja que praticamente inexiste controle sobre os julgamentos da Corte Constitucional brasileira, bem como será muito difícil corrigir uma decisão equivocada no futuro. Com efeito, até poderá o Poder Legislativo fazê-lo, já que uma decisão do STF no controle abstrato de constitucionalidade não obsta que o Legislativo aprove nova lei com o mesmo conteúdo da anteriormente declarada inconstitucional. Entretanto, as conjunturas institucionais desincentivam-no a editar nova lei contrária a uma decisão já tomada pelo STF, pois será provável que ele declare inconstitucional essa nova lei com o mesmo conteúdo. Tanto é que, proferida uma decisão pelo STF no controle abstrato, o Parlamento recebe esse pronunciamento como "decisão tomada", para utilizar a expressão comumente citada dentro do Congresso Nacional. Assim, fica extremamente difícil controlar o poder de revisão judicial no controle abstrato e concentrado de constitucionalidade.

De outro lado, quando se trata de controle difuso e concreto, o poder judicial de controle de constitucionalidade fica mais diluído entre as instâncias judiciais, permitindo ampla participação da sociedade e das mais diversas instituições. Além disso, como as decisões das instâncias judiciais inferiores estão sujeitas a recurso, o risco de decisões equivocadas é menor, ou, ao menos, haverá a possibilidade de instâncias judiciais superiores corrigirem os erros de instâncias judicias inferiores.

O procedimento do controle difuso e concreto certamente não elimina a possibilidade de que erros sejam cometidos ou de que uma decisão injusta seja 
tomada. Aliás, nenhum procedimento seria capaz de impedir isso. Mas, em termos de controle do poder controlador, não é somente isso o que importa. O que deve ser ressaltado é que, no controle difuso e concreto de constitucionalidade, mesmo após a decisão judicial para o caso individual transitar em julgado, eventual erro na interpretação constitucional poderá ser corrigido no futuro para outros casos, ou se poderá tomar uma decisão melhor diante da análise dos efeitos dinâmicos das decisões judiciais equivocadas. Assim, o controle difuso de constitucionalidade permite que se reconheçam as contingências de uma decisão judicial e mantém uma porta aberta para que, no futuro, possa ser dada uma nova interpretação.

Portanto, para que haja possibilidade de controle daquele que exerce o controle de constitucionalidade, é preciso que o órgão estatal que decide por último esteja sempre aberto à crítica das instituições e dos cidadãos, para que, com base em pressões populares ou numa nova visão sobre a questão, esse poder possa ceder e mudar a decisão.

\section{CONSIDERAÇÕES FINAIS}

A partir de tudo o que foi discutido, não se pode dizer que o controle abstrato e concentrado de constitucionalidade seja autoevidente. A necessidade de garantir a força normativa da Constituição, a sua superioridade em relação às demais normas e o controle de constitucionalidade não implicam inexoravelmente outorgar esse poder ao Judiciário ou à Corte Constitucional. É possível proteção efetiva à Constituição e aos direitos fundamentais em sistemas que deixam a última palavra em matéria de controle de constitucionalidade ao Legislativo, a depender de opções político-constitucionais e das instituições de cada país.

Além disso, já se demonstrou que o expansionismo da jurisdição constitucional no Brasil pode estar na contramão de direção da democracia, do pluralismo, do respeito à discordância e do desenvolvimento do projeto constitucional. Aliás, as pesquisas empíricas demonstram que a justificativa de proteção jurisdicional de direitos fundamentais não se sustenta, haja vista que é muito baixo o percentual de ações diretas de inconstitucionalidade que protegem direitos fundamentais.

Ademais, sob uma perspectiva que considera toda a complexidade social e institucional existente, chega-se à percepção de que o controle concentrado e 
abstrato de constitucionalidade, comparativamente ao controle difuso, não é mais democrático, tampouco a melhor maneira de proteger os direitos fundamentais. Nesse sentido, o controle difuso e concreto de constitucionalidade tem mais aptidão para, pragmaticamente, garantir o equilíbrio entre os Poderes Constituídos e permitir uma maior participação das demais instituições e dos cidadãos nos processos de tomada de decisão, o implica impedir que os direitos fundamentais sejam transformados em essencialismos fundamentadores de práticas despóticas de um dos Poderes em detrimento dos demais e da própria democracia.

A análise da capacidade das instituições brasileiras permite concluir que o processo de controle abstrato e concentrado de constitucionalidade não admite a participação da grande maioria das instituições que atuam na proteção dos direitos fundamentais em jogo, pois se restringe a poucos legitimados, previstos num pequeno rol estabelecido na Constituição. Além disso, pelo sistema adotado no Brasil, é possível que uma lei seja declarada inconstitucional no controle abstrato e concentrado sem que haja a sua defesa. Se isso não bastasse, esse modelo de controle de constitucionalidade tem grande potencial para gerar um desequilíbrio federativo, na medida em que existe ampla participação de entes federais nesse processo, em detrimento dos entes estaduais.

A análise dos diversos sistemas constitucionais também permite concluir que tão importante quanto definir a instituição que realizará 0 controle de constitucionalidade é estabelecer como o poder de controlar a constitucionalidade deve ser controlado. Para tanto, o órgão estatal responsável por dar a última palavra em termos de controle de constitucionalidade deve estar sempre aberto à fiscalização, à crítica e ao controle das outras instituições e dos cidadãos, para que, com base em pressões populares ou institucionais, esse poder seja suscetível a ceder e mudar a decisão. Nessa perspectiva, comparativamente ao controle concentrado e abstrato, no controle difuso e concreto de constitucionalidade, o poder de revisão judicial fica mais diluído entre as diversas instâncias judiciais, além do que se permite um maior controle interno e externo, realizado pelas diversas instituições e pelos cidadãos.

O controle de constitucionalidade não pode subtrair dos cidadãos a sua responsabilidade política na construção da nação e no desenvolvimento do projeto constitucional. Aliás, o projeto constitucional é um empreendimento comum, aberto, multifacetário, realizado pelas mais diversas instituições e por todos os cidadãos, um 
projeto que não pode ser reduzido a um único ator, muito menos à Corte Constitucional. Assim, o controle abstrato de constitucionalidade, por ser concentrado na Corte Constitucional, tende a fechar o projeto constitucional, ignorando a verdadeira identidade do sujeito constitucional. Nesse sentido, o controle difuso e concreto de constitucionalidade tem muito a contribuir com o experimentalismo institucional e o desenvolvimento da democracia.

Portanto, o controle de constitucionalidade deve ser apenas o medium pelo qual o Judiciário participa do projeto constitucional, sem fechar o diálogo com o futuro, com as demais instituições e com a sociedade. 


\section{REFERÊNCIAS}

BENVINDO, Juliano Zaiden. Ativismo judicial no Supremo Tribunal Federal: um debate sobre os limites da racionalidade. In: GUERRA, Luiz. (Org.). Temas contemporâneos do direito: homenagem ao bicentenário do Supremo Tribunal Federal. Brasília: Guerra, 2011.

A "última palavra", o poder e a história: O Supremo Tribunal Federal e o discurso de supremacia no constitucionalismo brasileiro. Revista de Informação Legislativa, Brasília, v. 51, n. 201, jan.-mar. 2014.

CÂMARA DOS DEPUTADOS. Projeto de Lei n. 4.559/2004. Disponível em: <http://www.camara.gov.br/proposicoesWeb/prop_mostrarintegra;jsessionid=2AA0F 15DA278794007CF9AEF857E7065. node2?codteor=256085\&filename=TramitacaoPL+4559/2004>. Acesso em: 21 jun. 2019.

BOBBIO, Norberto. O futuro da democracia (trad. Marco Aurélio Nogueira). 8. ed. São Paulo: Paz e Terra, 2000.

CONSELHO NACIONAL DE JUSTIÇA. Relatório Justiça em Números 2018: anobase 2017. Brasília: CNJ, 2018. Disponível em:

<http://www.cnj.jus.br/files/conteudo/arquivo/2018/09/8d9faee7812d35a58cee3d92d 2df2f25.pdf >. Acesso em 21 jun. 2019.

DERRIDA, Jaques. Força de Lei (trad. Leyla Perrone-Moisés). São Paulo: Martins Fontes, 2010.

FALCÃO, Joaquim; OLIVEIRA, Fabiana Luci de. O STF e a agenda pública nacional: de outro desconhecido a Supremo protagonista?. Lua Nova, São Paulo, n. 88, pp. 429-469, 2013.

KELSEN, Hans. Judicial Review of Legislation: A Comparative Study of the Austrian and the American Constitution. The Journal of Politics, v. 4, n. 2, pp. 183-200, may 1942.

KLAFKE, Guilherme Forma. Vícios no Processo Decisório do Supremo Tribunal Federal. 176 f. Monografia (Especialização). Escola de Formação da Sociedade Brasileira de Direito Público, São Paulo, 2010.

KOERNER, Andrei; FREITAS, Lígia Barros de. O Supremo na Constituinte e a Constituinte no Supremo. Lua Nova, São Paulo, n. 88, pp. 141-184, 2013.

LIMA, Roberto Kant de. Sensibilidades jurídicas, saber e poder: bases culturais de alguns aspectos do direito brasileiro em uma perspectiva comparada. Anuário Antropológico, Brasília, n. 2, p. 25-51, jul.-dez. 2009.

LINARES, Sebastián. El diálogo democrático entre las cortes y las instituciones representativas. Revista Mexicana de Sociología, México, a. 70, n. 3, p. 487-539, jul.-set. 2008. 
Medida Cautelar na Ação Direta de Inconstitucionalidade n. 926. Relator:

Ministro Sydney Sanches. Tribunal Pleno. Julgado em 01/09/1993. DJ 06-05-1994, p. 10484. Revista Trimestral de Jurisprudência, Brasília, v. 152-01.

MENDES, Conrado Hübner. Controle de constitucionalidade e democracia. Rio de Janeiro: Elsevier, 2008.

MENDES, Gilmar Ferreira; COELHO, Inocêncio Mártires; BRANCO, Paulo Gustavo Gonet. Curso de Direito Constitucional. 4. ed. São Paulo: Saraiva, 2009.

FUNDAÇÃO GETÚLIO VARGAS. Relatório ICJ (Índice de Confiança na Justiça): 1ำ semestre 2017. Brasil: FGV, 2017. Disponível em:

<http://bibliotecadigital.fgv.br/dspace/bitstream/handle/10438/19034/Relatorio-

ICJBrasil_1_sem_2017.pdf?sequence=1\&isAllowed=y>. Acesso em 21 jun. 2019.

SUNDFELD, Carlos Ari; SOUZA, Rodrigo Pagani. Accountability e jurisprudência do STF: estudo empírico de variáveis institucionais e estrutura das decisões. In: VOJVODIC, Adriana; PINTO, Henrique Motta; GORZONI, Paulo; SOUZA, Rodrigo Pagani de. Jurisdição Constitucional no Brasil. São Paulo: Malheiros, 2012. pp. 75-116.

SENADO FEDERAL. Informações apresentadas em 2/3/2012 pelo Presidente do Senado Federal e a Advocacia-Geral do Senado na ADI 4424. Disponível em: <http://redir.stf.jus.br/estfvisualizadorpub/jsp/consultarprocessoeletronico/ConsultarP rocessoEletronico.jsf?seqobjetoincidente=3897992>. Acessoem: 21 jun. 2019.

SUNSTEIN, Cass R.; VERMEULE, Adrian. Interpretation and Institutions. Michigan Law Review, v. 101, p. 885-951, fev. 2003.

\section{SUPREMO TRIBUNAL FEDERAL.Estatísticas do STF:acervo processual.}

Disponível em:

$<$ http://portal.stf.jus.br/textos/verTexto.asp?servico=estatistica\&pagina=acervoatual >. Acesso em: 21 jun. 2019.

Recebido em 05/07/2019 Aprovado em 11/10/2019

Received in 05/07/2019

Approved in 11/10/2019 